Jurnal Agroteknologi, Vol. 7 No. 1, Agustus $2016: 33$ - 40

\title{
KEANEKARAGAMAN SERANGGA PADA TUMPANGSARI TANAMAN PANGAN SEBAGAI TANAMAN SELA DI PERTANAMAN KELAPA SAWIT BELUM MENGHASILKAN
}

\author{
(Insect Diversity on Intercropping System in Young Palm Oil) \\ LUTFI ARIFIN, MOKHAMAD IRFAN, INDAH PERMANASARI, AULIA RANI ANNISAVA, \\ DAN AHMAD TAUFIQ ARMINUDIN \\ Program Studi Agroteknologi, Fakultas Pertanian dan Peternakan \\ Universitas Islam Negeri Sultan Syarif Kasim Riau \\ JI. H.R. Soebrantas No. 155 KM 18 Simpang Baru Panam Pekanbaru Riau 28293
}

\begin{abstract}
Plant intercropping that interplanted with young palm oil plantation indicated that there was change on ecosystem balance which resulted diversity alteration of insect as bio indicator area. The objective of the research was to obtain information on diversity of insect related to its intercropping system interplanted with young palm oil plantation. The research was conducted from December 2015 to February 2016 at privately-owned oil palm plantation, Kualu district, Kampar regency, Riau province. Descriptive methods by range survey on corn monoculture, soybean monoculture, bera, between corn and soybean intercropping in young palm oil area were used as experimental methods. Insect sampling was conducted by using pitfall trap, sweeping net and hand collection at 16 research units. The result showed that there were ten different insect ordo consisted of 50 families in all intercropping system sampled in this study. Diversity index $\left(H^{\prime}\right)$ reached as high as 3.07 with the best average $(E=0.07)$ that was observed in soybean monoculture. Corn - soybean intercropping posessed the highest point of insect dominance (0.34), which is mean that there was only one kind of insect dominated on the community. The utilization of soybean monoculture system interplanted in young palm oil plantation is best to be used as a reference of ecological indicator on environment utilization, due to the reason that the existence of pest is balanced by the predator.
\end{abstract}

Keywords: insects diversity, intercropping, young oil palm, and plantation

\section{PENDAHULUAN}

Perkebunan kelapa sawit berperan sebagai penyedia lapangan kerja, sumber pendapatan utama petani, sumber pendorong pertumbuhan wilayah dan sumber pelestari lingkungan. Perkebunan kelapa sawit di Indonesia saat ini telah mencapai lebih dari 11 juta hektar, sehingga merupakan komoditas perkebunan terluas di Indonesia maupun di dunia (Dirjenbun, 2015). Semakin meluasnya perkebunan kelapa sawit dapat membatasi wilayah penanaman tanaman pangan, sedangkan kebutuhan jagung dan kedelai masih impor.

Pembukaan lahan baru seluas 4,7 juta hektar dapat memenuhi kebutuhan pangan nasional (Marlina, 2013). Permasalahan pangan nasional diatasi dengan solusi pembuka lahan bukaan baru. Solusi yang dapat diterapkan yaitu memanfaatkan lahan replanting karena pada tanaman sawit belum menghasilkan (TBM) 1 ada sekitar 75\% ruang terbuka dan pada TBM 2 ada $60 \%$ ruang terbuka (Mawarni, 2011). Tanaman kedelai dan jagung dapat dijadikan tanaman sela pada perkebunan kelapa sawit belum menghasilkan sebagai upaya optimalisasi lahan. Tanaman jagung dan kedelai dapat menggantikan tanaman penutup tanah pada perkebunan kelapa sawit yang umumnya bukan tanaman pangan.

Dinas Perkebunan Provinsi Riau (2013) melaporkan luas perkebunan kelapa sawit rakyat di Riau mencapai 1.315.231 ha dan luas perkebunan kelapa sawit besar nasional dan swasta nasional 1.057.171 ha. Jika replanting dilakukan setiap 30 tahun, maka potensi luas lahan replanting mencapai 35.239 ha per tahun dan apabila diasumsikan 50\% layak tanam, akan didapatkan lahan seluas 17.600 ha per tahun. Artinya potensi untuk memanfaatkan lahan replanting sebagai lahan alternatif untuk tanaman pangan memiliki peluang yang besar.

Harahap et al. (2008) melaporkan bahwa tumpangsari kelapa sawit belum menghasilkan dengan kedelai menghasilkan 1,8 ton/ha dan terbukti tidak mengganggu pertumbuhan kelapa sawit. Tumpangsari jagung dan kelapa sawit berhasil memperoleh jagung pipilan 0,9-2,6 ton/ha (Herman dan 
Pranowo, 2011). Potensi ini dapat diterapkan untuk memenuhi kebutuhan pangan daerah.

Tumpangsari tanaman pangan sebagai tanaman sela di perkebunan kelapa sawit belum menghasilkan, mengindikasikan adanya perubahan keseimbangan ekosistem. Perubahan keseimbangan ekosistem akan mengakibatkan perubahan keanekaragaman serangga sebagai bioindikator lingkungan, sehingga organisme yang hidup di sekitar tanaman pada sistem tumpangsari ini dapat menjadi tolak ukur pemanfaatan alam yang baik atau justru merusak lingkungan. Penelitian ini bertujuan untuk mengetahui keanekaragaman serangga yang berasosiasi di lahan tumpangsari jagung, kedelai, dan kelapa sawit belum menghasilkan.

\section{BAHAN DAN METODE}

Penelitian dilakukan pada bulan Desember 2015 sampai Februari 2016 di kebun kelapa sawit belum menghasilkan (TBM) milik warga di Kelurahan Kualu, Kecamatan Tambang, Kabupaten Kampar. Identifikasi serangga dilakukan di Laboratorium Patologi, Entomologi, dan Mikrobiologi (PEM) Fakultas Pertanian dan Peternakan UIN Sultan Syarif Kasim Riau dan di Laboratorium Entomologi Dasar Fakultas Pertanian Universitas Gadjah Mada Yogyakarta. Alat yang digunakan dalam penelitian ini adalah plastik ukuran $2 \mathrm{~kg}$, pinset, kaca pembesar (lup), kamera digital, botol spesimen, jaring serangga, pitfall traps, mikroskop, ember, plastik klip, kuas, nampan, buku identifikasi dan alat tulis. Bahan yang digunakan adalah alkohol $70 \%$, klorofom, tisu, aquades, detergen dan kertas label.

Metode yang digunakan dalam penelitian ini adalah metode deskriptif kuantitatif dengan melakukan survei lapangan pada monokultur jagung, monokultur kedelai, bera serta tumpangsari jagung dan kedelai pada sela tegakan kelapa sawit. Pengambilan sampel serangga dilakukan dengan metode yang dimodifikasi dari Arminudin et al. (2010), Radiyanto et al. (2010), Tambunan et al. (2013) dan Masfiyah et al. (2014) dengan tehnik observasi (hand collection), jaring (swepping net) dan jebakan (pitfall traps) pada 16 unit percobaan.

\section{HASIL DAN PEMBAHASAN}

\section{Gambaran Umum Tempat Penelitian}

Kelurahan Kualu, Kecamatan Tambang, Kabupaten Kampar terletak pada titik koordinat $101^{\circ} 17$ '22" BT dan 00 26'56" LU. Sebelah Barat berbatasan dengan kelurahan Terantang, sebelah Timur berbatasan dengan kelurahan Teluk Kenidai sebelah Utara berbatasan dengan Tarai Bangun, sebelah Selatan berbatasan kelurahan Sialang Kubang. Kelurahan Kualu terletak pada ketinggian antara 5-10 $\mathrm{m} / \mathrm{dpl}$ dengan kemiringan lereng $0 \%-2 \%$ artinya mempunyai wilayah yang datar (BMKG, 2016). Kondisi lokasi penelitian memiliki suhu udara antara $26,1^{\circ} \mathrm{C}-27,6{ }^{\circ} \mathrm{C}$. Kelembaban relatif udara antara $80 \%-85 \%$. Data iklim pada tahun 20152016 dapat dilihat pada Tabel 1.

Tabel 1. Data Iklim di Kota Pekanbaru Pada Saat Penelitian

\begin{tabular}{lrrrr}
\hline Parameter Iklim & \multicolumn{4}{c}{ Bulan } \\
\hline & Oktober & November & Desember & 2016 \\
& 27,0 & 26,1 & 27,0 & 27,6 \\
\hline Temperatur rata-rata ${ }^{\circ} \mathrm{C}$ & 64,7 & 411,4 & 317,1 & 129,3 \\
Curah hujan (mm/hari) & 85,0 & 82,0 & 85,0 & 80,0
\end{tabular}

Sumber: BMKG, 2016

Pada Tabel 1. rata-rata temperatur selama pengambilan sampel yaitu $26,1^{\circ} \mathrm{C}$ $27,6^{\circ} \mathrm{C}$, dan rata-rata curah hujan pada bulan Oktober 2015 sampai dengan Januari 2016 berkisar 64,7 - 411,4 (mm/hari). Rata-rata kelembaban pada saat penelitian $80 \%-85 \%$. Kondisi tanah di lahan penelitian rata-rata $\mathrm{pH}$ tanah 5,34. Vegetasi sekitar lahan penelitian berupa gulma antara lain, babandotan, rumput teki, putri malu, ilalang dan tumbuhan merambat.

Jarak tanam kelapa sawit $8 \times 9 \mathrm{~m}$ dengan panjang kanopi $2 \mathrm{~m}$, sehingga terdapat $75 \%$ ruang terbuka diantara tegakan kelapa sawit belum menghasilkan. Kajian Mawarni (2011) membuktikan tanaman sawit belum menghasilkan (TBM) 1 ada sekitar $75 \%$ ruang terbuka dan pada TBM 2 ada $60 \%$ ruang terbuka. Ruang terbuka diantara tegakan kelapa sawit belum menghasilkan dapat dimanfaatkan dengan mengolah $5 \times 5$ $\mathrm{m}$. Penelitian dilakukan dengan 4 perlakuan yaitu bera, monokultur jagung, monokultur kedelai, tumpangsari jagung-kedelai. Bera adalah perlakuan tanpa penanaman tanaman pangan (kontrol) atau dibiarkan kosong tanpa 
tanaman, hal ini dilakukan agar diketahui keefektivitasan penanaman tanaman pangan disela tegakan kelapa sawit.

\section{Identifikasi Serangga}

Hasil identifikasi serangga yang berhasil dikoleksi terdiri atas 10 ordo dengan 50 famili, dapat dilihat pada Tabel 2. Pengambilan sampel serangga telah dilakukan dengan metode jebakan (pitfall traps), jaring serangga (swepping net), dan observasi (hand collection).

Tabel 2. Hasil Identifikasi Serangga

\begin{tabular}{|c|c|c|c|c|}
\hline & Ordo & No & Famili & Peran Ekologis \\
\hline & Blattodea & $\begin{array}{l}1 \\
2\end{array}$ & $\begin{array}{l}\text { Blattidae } \\
\text { Blattellidae }\end{array}$ & $\begin{array}{l}\text { Pemakan Bahan Organik } \\
\text { Pemakan Bahan Organik }\end{array}$ \\
\hline 2 & Coleoptera & $\begin{array}{l}1 \\
2 \\
3 \\
4 \\
5 \\
6 \\
7 \\
8 \\
9\end{array}$ & $\begin{array}{l}\text { Anthicidae } \\
\text { Carabidae } \\
\text { Coccinellidae } \\
\text { Chrysomelidae } \\
\text { Cantharidae } \\
\text { Elateridae } \\
\text { Nitidulidae } \\
\text { Scarabaeidae } \\
\text { Staphylinidae }\end{array}$ & $\begin{array}{l}\text { Pemakan Bahan Organik } \\
\text { Predator } \\
\text { Predator } \\
\text { Herbivora } \\
\text { Predator } \\
\text { Pemakan Bahan Organik } \\
\text { Pemakan Bahan Organik } \\
\text { Pemakan Bahan Organik } \\
\text { Predator }\end{array}$ \\
\hline 3 & Dermaptera & 1 & Forficulidae & Predator \\
\hline 4 & Diptera & $\begin{array}{l}1 \\
2 \\
3 \\
4 \\
5 \\
6\end{array}$ & $\begin{array}{l}\text { Ceratopogonidae } \\
\text { Asilidae } \\
\text { Dolicophodidae } \\
\text { Phoridae } \\
\text { Micropezidae } \\
\text { Tachinidae } \\
\end{array}$ & $\begin{array}{l}\text { Pemakan Bahan Organik } \\
\text { Predator } \\
\text { Predator } \\
\text { Pemakan Bahan Organik } \\
\text { Herbivora } \\
\text { Parasitoid }\end{array}$ \\
\hline 5 & Hemiptera & $\begin{array}{c}1 \\
2 \\
3 \\
4 \\
5 \\
6 \\
7 \\
8 \\
9 \\
10\end{array}$ & $\begin{array}{l}\text { Alydidae } \\
\text { Cercopidae } \\
\text { Cicadellidae } \\
\text { Delphacidae } \\
\text { Derbidae } \\
\text { Flatidae } \\
\text { Lygaeidae } \\
\text { Pentatomidae } \\
\text { Plataspididae } \\
\text { Reduviidae }\end{array}$ & $\begin{array}{l}\text { Herbivora } \\
\text { Herbivora } \\
\text { Herbivora } \\
\text { Herbivora } \\
\text { Herbivora } \\
\text { Herbivora } \\
\text { Herbivora } \\
\text { Herbivora } \\
\text { Herbivora } \\
\text { Predator }\end{array}$ \\
\hline 6 & Hymenoptera & $\begin{array}{l}1 \\
2 \\
3 \\
4 \\
5 \\
6 \\
7\end{array}$ & $\begin{array}{l}\text { Apidae } \\
\text { Braconidae } \\
\text { Formicidae } \\
\text { Odontomachus } \\
\text { Pteromalidae } \\
\text { Sphecidae } \\
\text { Vespidae }\end{array}$ & $\begin{array}{l}\text { Predator } \\
\text { Predator } \\
\text { Predator } \\
\text { Predator } \\
\text { Predator } \\
\text { Predator } \\
\text { Predator }\end{array}$ \\
\hline 7 & Isoptera & 1 & Termitidae & Pemakan Bahan Organik \\
\hline 8 & Lepidoptera & $\begin{array}{l}1 \\
2 \\
3 \\
4 \\
5 \\
6 \\
7 \\
8\end{array}$ & $\begin{array}{l}\text { Amatidae } \\
\text { Geometridae } \\
\text { Lymantriidae } \\
\text { Arctiidae } \\
\text { Noctuidae } \\
\text { Nymphalidae } \\
\text { Satyridae } \\
\text { Pyralidae }\end{array}$ & $\begin{array}{l}\text { Herbivora } \\
\text { Herbivora } \\
\text { Herbivora } \\
\text { Herbivora } \\
\text { Herbivora } \\
\text { Herbivora } \\
\text { Herbivora } \\
\text { Herbivora }\end{array}$ \\
\hline 9 & Mantodea & 1 & Mantidae & Predator \\
\hline 10 & Orthoptera & $\begin{array}{l}1 \\
2 \\
3 \\
4 \\
5\end{array}$ & $\begin{array}{l}\text { Acrididae } \\
\text { Gryllidae } \\
\text { Pyrgomorphidae } \\
\text { Tetrigidae } \\
\text { Tettigoniidae }\end{array}$ & $\begin{array}{l}\text { Herbivora } \\
\text { Herbivora } \\
\text { Herbivora } \\
\text { Pemakan Bahan Organik } \\
\text { Herbivora }\end{array}$ \\
\hline
\end{tabular}


Menurut Boror et al. (2005) ordo Blattodea merupakan serangga primer pada daerah tropis, sebagian besar berperan sebagai dekomposer yang bermanfaat bagi kesuburan tanah. Terdapat dua famili yang ditemukan pada penelitian ini yaitu famili Blattidae dan famili Blatellidae. Ordo Blattodea lebih banyak ditemukan pada pertanaman kedelai, hal ini dikarenakan habitat ordo Blattodea didalam reruntuhan seresah daun kedelai yang sudah rontok atau ditumpukan seresah gulma. Ordo Blattodea bersifat hama saat di rumah dan dapur, tetapi bersifat menguntungkan saat berada di kebun dan pekarangan (Kalsoven, 1981).

Ordo Coleoptera biasanya memiliki sayap depan yang keras seperti tanduk tenpa vena, kedua sayap biasanya bertemu satu sama lain membentuk sebuah garis lurus kebawah pada tengah-tengah punggung (Boror et al., 2005). Menurut Kalsoven, (1981) tipe mulut dalam ordo ini adalah tipe chewing (penggigit). Serangga ordo Coleoptera yang ditemukan antara lain berasal dari famili Staphylinidae, Cocinellidae, Chrysomelidae, Anthicidae, Cantahidae, Elateridae, Carabidae, Scarabaeidae dan Nitidulidae. Peran ekologis sebagai dekomposer pada family Elateridae, Nitidulidae dan Scarabaeoidae. Family Anthisidae berperan sebagai pemakan jamur, sedangkan family Cryshomellidae berperan sebagai herbivora. Peledakan hama famili Cryshomellidae pada petakan tumpangsari disebabkan karena hilangnya habitat asli.

$$
\text { Ciri khas dari serangga ordo }
$$

Dermaptera yang ditemukan antara lain mudah dikenali dengan adanya cerci yang berbentuk seperti catut, sayap depan berkurang menjadi tegmina, bermembran dan sayap belakang lebar (Boror et al., 2005). Famili yang ditemukan dalam penelitian ini adalah family Forficullidae. Menurut Kalsoven, (1981) serangga yang termasuk ordo Dermaptera aktif pada malam hari untuk memakan telur dan larva dari serangga kecil.

Memiliki sepasang sayap, memiliki membran dengan system syaraf, kaki depannya dikembangkan sedangkan kaki belakang dikurangi merupakan ciri-ciri dari ordo Diptera (Boror et al., 2005). Serangga yang merupakan famili dari ordo Diptera antara lain, Asilidae, Ceratopogonidae, Dolicophodidae, Phoridae, Mikropezidae, dan Tachinidae.

Kalshoven (1981), menjelaskan bahwa ciri-ciri dari ordo Hemiptera antara lain memiliki sayap yang tebal pada dasar dan bermembran pada ujung (hemelytra) yang overlapping pada ujung yang lainnya, paruhnya muncul dari depan atau dari belakang kepala. Famili yang ditemukan adalah Alydidae, Cercopidae, Cicadellidae, Delphacidae, Derbidae, Flatidae, Lygaeidae, Pentatomidae, Plataspididae dan Reduviidae. Seluruh famili yang ditemukan berperan sebagai hama tanaman, kecuali famili Reduviidae yang berstatus sebagai predator (Boror et al., 2005).

Ordo Hymenoptera memiliki ciri-ciri antara lain sayap depan yang berbeda ukuran dengan sayap belakang, tajam dan berpembuluh, antena biasanya membengkok, berbentuk seperti pemukul. Famili Apidae, Braconidae, Formicidae, Odontomachus, Pteromalidae, Sphecidae, dan Vespidae adalah famili yang ditemukan dari ordo Hymenoptera. Famili Formicidae merupakan famili yang paling banyak ditemukan. Sebagian besar jenis semut (Formicidae) adalah predator utama bagi serangga lain (Boror et al., 2005).

Ordo Isoptera yang ditemukan adalah famili Termitidae yang memiliki ciri-ciri mandible menyusut, kepala menjulur kedepan menjadi tonjolan seperti hidung yang panjang. Kelompok ini mencakup rayap-rayap tanpa serdadu dan rayap-ratap bentuk hidung panjang. Rayap-rayap tanpa serdadu membuat lubang dibawah kayu atau lempengan-lempengan fases sapi dan berperan sebagai dekomposer (Boror et al., 2005).

Ordo Lepidoptera adalah serangga yang umum dan mudah untuk dikenal oleh setiap orang, karena dapat langsung dikenali oleh sisik-sisik pada sayap sayap yang lepas seperti debu pada jari seseorang apabila serangga ini dipegang. Tipe mulut pada pada ordo ini yaitu untuk menghisap makannnya (sponging). Ordo Lepidoptera memiliki ciri-ciri kedua pasang membran sayap tertutup secara luas dengan skala yang overlapping, bagian mulut dalam gulungan proboscis (bagian mulut yang diperpanjang), antena dengan segmen yang banyak (Boror et al., 2005). Famili yang ditemukan antara lain Amatidae, Geometridae, Lymantriidae, Noctuidae, Nymphalidae dan Pyralidae. Seluruh famili yang ditemukan berperan sebagai hama tanaman.

Menurut Kalsoven (1981), ciri khas ordo Mantodea memiliki sepasang kaki depan bersifat seperti menyembah, memiliki 3 pasang kaki. Dua pasang kaki belakang di gunakan untuk berjalan sedangkan sepasang kaki depan berguna untuk menangkap mangsa. Famili yang ditemukan adalah Mantidae yang memiliki peranan ekologis sebagai predator (Boror et al., 2005).

Ordo Orthoptera biasanya memiliki kaki belakang dengan femur yang membesar yang digunakan untuk meloncat dengan ukuran 
lebih dari $5 \mathrm{~mm}$, protonum dengan cabang cuping samping turun sebesar punggung di atas abdomen, coxae (segmen pertama dari kaki serangga) yang kecil dan terpisah dengan baik, memiliki antena yang pendek hingga panjang. Famili yang ditemukan adalah Acrididae, Gryllidae, Pyrgomophidae, Tetrigidae dan Tettigoniidae. Peran ekologis ordo Orthoptera sebagai herbivora kecuali famili Tetrigidae yang berperan sebagai pemakan jamur.

\section{Indeks Keanekaragaman (H'), Keseragaman (E) dan Dominansi (D)}

Indeks keanekaragaman, keseragaman

dan dominansi pada suatu lokasi menggambarkan adanya kekayaan jenis famili di lokasi tersebut. Nilai indeks keanekaragaman tergantung variasi jumlah individu tiap famili yang didapatkan, sehingga makin kecil jumlah famili dan variasi jumlah individu tiap spesies, maka keanekaragaman suatu ekosistem akan semakin kecil, demikian juga sebaliknya. Serangga merupakan satu diantara bioindikator kesehatan lingkungan yang dapat digunakan untuk menjadi tolak ukur pemanfaatan alam yang baik atau justru merusak lingkungan. Lingkungan yang telah dialih fungsikan menjadi ekosistem baru dengan campur tangan manusia akan mengalami perubahan ekosistem. Penggunaan serangga sebagai bioindikator dirasa penting dengan tujuan menggambarkan adanya ketertarikan dengan kondisi faktor biotik dan abiotik lingkungan. Hasil dari indeks keanekaragaman serangga (Tabel 3) menjelaskan keanekaragaman yang didapatkan dari penelitian ini.

Tabel 3. Nilai Indeks Keanekaragaman, Indeks Kemerataan dan Dominansi pada pertanaman monokultur jagung, monokultur kedelai, dan tumpangsari jagung-kedelai di tegakan kelapa sawit belum menghasilkan

\begin{tabular}{lcccc}
\hline & Jagung & Kedelai & Jagung-Kedelai & Bera \\
\hline Indeks Keanekaragaman $\left(\mathrm{H}^{\prime}\right)$ & 2,84 & 3,07 & 1,95 & 2,37 \\
Indeks Keseragaman $(\mathrm{E})$ & 0,07 & 0,07 & 0,03 & 0,07 \\
Dominansi $(\mathrm{D})$ & 0,09 & 0,07 & 0,34 & 0,20 \\
\hline
\end{tabular}

Hasil analisis pada Tabel 3. diketahui bahwa serangga yang diperoleh pada empat model pertanaman mempunyai keanekaragaman jenis yang berbeda. Indeks keanekaragaman tumpangsari jagung-kedelai paling rendah yaitu 1,95 artinya keanekaragaman serangga tergolong sedang. Rendahnya keanekaragaman disebabkan tidak adanya keseimbangan ekosistem. Pada fase vegetatif terjadinya peledakan hama famili Cryshomelidae. Hal ini disebabkan perubahan lingkungan atau cara budidaya, yang biasanya tidak ditanamai tanaman pangan. Selain itu, peledakan hama juga dipengaruhi dari perpindahan habitat asli yang telah rusak. Berbeda dengan kajian Suleman et al. (2013) bahwa penanaman tumpangsari jagungkedelai dapat menekan $50 \%$ kerugian yang diakibatkan hama.

Nilai indeks keanekaragaman pada bera 2,37 (sedang), artinya keanekaragaman pada ekositem cukup dipengaruhi oleh lingkungan. Nilai indeks keanekaragaman berkaitan dengan kondisi lingkungan dari komunitas tersebut. Indeks keanekaragaman pada ekosistem yang secara fisik dikendalikan memiliki nilai rendah sedangkan pada ekositsem alami memiliki nilai yang tinggi (Sanjaya dan Dibiyantoro, 2012). Nilai indeks kemerataan menunjukkan kesempatan yang dimiliki oleh masing-masing individu di dalam komunitas tersebut untuk menjalankan fungsifungsi ekologisnya (Haneda et al., 2013). Peranan ekologis serangga pada bera dapat dilihat pada Gambar 4.12. Nilai kemerataan pada bera adalah 0,07 artinya nilai ini mendekati 1 maka tiap individu dalam ekositem ini dapat menjalankan fungsinya baik sebagai hama, predator, parasitoid dan dekomposer.

Nilai indeks keanekaragaman pada monokultur tergolong sedang. Berbeda dengan kajian Suleman (2013) yang menyatakan keanekragaman sergolong sangat rendah yaitu 0,09 . Hal ini dipengaruhi faktor lingkungan pada saat penelitian yaitu suhu $29,9{ }^{\circ} \mathrm{C}$, kelembaban $85 \%$ dan intensitas cahaya 24-25 lux merupakan karakteristik lingkungan yang sesuai dengan jenis serangga tersebut. Susilo dan Swiba (2001) melaporkan kehadiran suatu habitat dipengaruhi oleh faktor-faktor lingkungan antara lain kemampuan serangga tersebut menyebar, seleksi habitat, kondisi suhu udara, kelembaban udara, kelembaban tanah, cahaya, curah hujan, vegetasi dan ketersediaan makanan.

Satu diantar upaya untuk meningkatkan produktifitas jagung nasional adalah dengan menanam tanaman jagung di sela tegakan kelapa sawit belum menghasilkan. Hasil penelitian Herman dan 
Pranowo (2011) memperoleh 0,9-2,6 ton/ha jagung pipilan kering dan tambahan pendapatan 1,9-5,2 juta rupiah per musim tanam. Pola tanam monokultur jagung memiliki nilai indeks keanekaragaman 2,84 (sedang), sehingga keanekaragaman serangga pada pola tanam ini cukup dipengaruhi oleh lingkungan. Artinya, pengaruh lingkungan seperti pemupukan, penyiangan gulma dan penyiraman berpengaruh pada keanekaragaman serangga.

Nilai indeks keanekaragaman pada monokultur jagung tergolong sedang. Berbeda dengan kajian Suleman (2013) yang menyatakan keanekaragaman serangga pada monokultur jagung tergolong sangat rendah. $\mathrm{Hal}$ ini dipengaruhi faktor lingkungan pada saat penelitian yaitu suhu $29,9{ }^{\circ} \mathrm{C}$, kelembaban $85 \%$ dan intensitas cahaya 24-25 lux merupakan karakteristik lingkungan yang sesuai dengan jenis serangga tersebut. Menurut Swaminathan (2011) dampak dari global warming dapat mengubah status serangga menjadi hama tanaman. Pemanfaatan potensi lingkungan seperti ini merupakan pemanfaatan alam yang berazas pemanfaatan ekosistem secara seimbang dan serasi. Dalam UU RI Tahun 1990 tentang Konservasi Sumberdaya Alam Hayati dan Ekosistem, dijelaskan bahwa konservasi sumberdaya alam hayati harus berazas pelestarian lingkungan secara serasi dan seimbang.

Pemanfaatan tanaman sela perkebunan kelapa sawit belum menghasilkan dengan pola monokultur kedelai menghasilkan 1,8 ton/ha atau dengan nilai 5.228.417,- per musim tanam dan pertumbuhan kelapa sawit belum menghasilkan tidak terganggu oleh pola tumpangsari tersebut (Harahap et al., 2008). Pada monokultur kedelai nilai indeks keanekaragaman serangga paling tinggi yaitu 3,07 , artinya keanekaragaman tidak dipengaruhi lingkungan. Hal ini diduga jenis organisme dalam keadaan seimbang dengan populasi organisme lain dalam komunitasnya. Maka pola tanam monokultur kedelai sebagai tanaman sela perkebunan kelapa sawit belum menghasilkan dapat dijadikan bioindikator pemanfaatan alam yang baik.

Menurut kajian Radiyanto et al. (2010) keseimbangan ekosistem terjadi karena adanya mekanisme pengendalian yang bekerja secara umpan balik negatif yang berjalan pada tingkat antar spesies dan tingkat inter spesies. Susilo dan Swiba (2001) melaporkan kehadiran suatu habitat dipengaruhi oleh faktor-faktor lingkungan antara lain kemampuan serangga tersebut menyebar, seleksi habitat, kondisi suhu udara, cahaya, curah hujan, vegetasi dan ketersediaan makanan.

Haneda et al. (2013) menyatakan keanekaragaman jenis serangga dipengaruhi oleh faktor kualitas dan kuantitas makanan, antara lain banyaknya tanaman inang yang cocok, kerapatan tanaman inang, umur tanaman inang, dan komposisi tegakan. Keadaan ekosistem seimbang tampak dari jenis serangga yang terperangkap sangat beraneka ragam dan populasi serangga merugikan, musuh alami serta serangga berguna berada dalam keadaan seimbang.

Didapatkan berbagai jenis serangga yang berperan merugikan dan menguntungkan. Apabila musuh alami mampu berperan sebagai pemangsa secara optimal sejak awal, maka populasi hama dapat berada pada tingkatan equilibrium position atau fluktuasi populasi hama dan musuh alami menjadi seimbang sehingga tidak akan terjadi ledakan hama. Predator umumnya bersifat polyphagous, yaitu dapat memangsa lebih dari satu mangsa dan tidak tergantung pada satu mangsa (Henuhili et al, 2013). Kemampuan musuh-musuh alami sebenarnya mampu mengendalikan lebih dari $99 \%$ serangga agar tetap berada pada jumlah yang tidak merugikan, sehingga pengendalian hama terpadu secara sengaja mendayagunakan dan memperkuat peranan musuh alami sebagai pengendali ledakan populasi hama. Menurut Marwoto (2007) berdasarkan kemampuan memangsa, siklus hidup, laju pertumbuhan, populasi dan umur serangga dewasa, maka suatu predator dapat menurunkan populasi suatu serangga hama secara signifikan.

Menurut Henuhili et al, (2013) menyatakan kemampuan memangsa berfluktuasi, antara lain dipengaruhi oleh kepadatan mangsanya, semakin bertambah banyak populasi mangsa maka pemangsaan bertambah banyak. Musuh alami merupakan sumberdaya alam hayati yang sangat penting untuk dikonservasi (dilestarikan), mengingat peranannya dalam pengendalian hayati hama pada ekosistem.

Subiyakto (2011) menyatakan faktorfaktor yang mengatur kepadatan suatu populasi dapat terjadi karena perubahan lingkungan kimia akibat adanya sekresi dan metabolisme, kekurangan makanan, serangan predator/parasit/penyakit, emigrasi faktor iklim misalnya cuaca, suhu dan kelembaban. Nilai indeks dominansi $<1$ maka jumlah spesies serangga beranekaragam, sebaliknya nilai indeks dominansi $=1$ maka tidak ada keberagaman dan kemerataan suatu serangga di dalam ekosistem tersebut. Nilai dominansi disebabkan kemampuan adaptasi yang baik, 
sehingga dapat menunjang kehidupan habitatnya. Berdasarkan tabel 4.3. nilai dominansi tumpangsari jagung-kedelai 0,34. Nilai dominansi yang paling tinggi dibanding pola tanam yang lain, hal ini dikarenakan adanya suatu jenis serangga yang dominan pada ekosistem ini. Tingginya nilai dominansi dipengaruhi faktor biotik dan abiotik. Satu diantara faktor abiotik adalah pengaruh lingkungan.

Rata-rata kelembaban pada saat penelitian $80 \%-85 \%$. Kondisi tanah di lahan penelitian rata-rata $\mathrm{pH}$ tanah 5,34. Vegetasi sekitar lahan penelitian berupa gulma antara lain, babandotan, rumput teki, putri malu, ilalang dan tumbuhan merambat. Menurut kajian Sanjaya dan Dibiyantoro (2012) tingkat dominansi dipengaruhi oleh faktor lingkungan seperti kelembaban udara, kelembaban tanah, suhu udara, suhu tanah dan $\mathrm{pH}$ tanah. Berdasarkan Gambar 4.18 dapat diketahui bahwa terjadinya peledakan serangga hama famili Cryshomellidae, hal ini diduga serangga tersebut mengalami migrasi dari areal bukaan baru berpindah ke areal yang telah dikelola untuk dijadikan budidaya. Berbeda dengan kajian Suleman et al (2013) bahwa penanaman tumpangsari jagung-kedelai dapat menekan $50 \%$ kerugian yang diakibatkan hama.

Peledakan populasi dapat terjadi jika suatu spesies dimasukkan ke dalam suatu daerah baru, dimana terdapat sumber-sumber yang belum dieksploitir oleh manusia dan tidak ada interaksi negatif, dimana sebenarnya predator dan parasit memainkan peranan dalam menahan peledakan populasi dan memang menekan laju pertumbuhan populasi (Subiyakto, 2011). Kemampuan dominansi famili Cryshomellidae yang tinggi ini diduga berkaitan dengan kurangnya tingkat pencemaran dan gangguan pada komunitas tersebut. Rendahnya nilai indeks keanekaragaman serangga secara langsung akan mengurangi terjadinya kompetisi interspesies yang dapat memicu munculnya dominansi dari suatu jenis serangga.

\section{KESIMPULAN DAN SARAN}

\section{Kesimpulan}

Serangga yang didapatkan pada tumpangsari jagung-kedelai-kelapa sawit menggunakan metode jebakan (pitfall traps), jaring (swepping net) dan observasi (hand collection) mendapatkan 10 ordo serangga dengan 50 famili. Nilai indeks keanekaragaman serangga yang tertinggi pada sistem tumpangsari kedelai-kelapa sawit, sedangkan pada tumpangsari jagung-kelapa sawit, jagung-kedelai-kelapa sawit, dan bera di sela tegakan kelapa sawit bernilai sedang. Nilai kemerataan serangga yang berasosiasi pada pertanaman tumpangsari jagung-kedelaikelapa sawit memiliki variasi yang cenderung sama, sedangkan pada tumpangsari jagungkedelai terdapat dominansi tertinggi dibandingkan dengan sistem tumpangsari yang lain, yang mendominasi serangga dalam famili Cryshomelidae yang berperan sebagai herbivora.

\section{DAFTAR PUSTAKA}

Arminudin, A.T., A. Wijonarko, dan Y. Andi Trisyono. 2010. Populasi Bemisia tabaci (Gennadius) pada pertanaman cabai di Yogyakarta: studi kasus pada daerah endemik dan non endemik penyakit keriting kuning cabai. Jurnal Agroteknologi, 1(1):14-18

Badan Meteorologi Klimatologi dan Geofisika. 2016. Data Bulanan Iklim Provinsi Riau tahun 2015-2016. Pekanbaru

Borror, D.J., C.A. Triplehorn and N.F. Jhonson. 2005. Study of Insect. Thomson Learning: Singapore. 864 hal.

Dinas Perkebunan Provinsi Riau. 2013. Statistik Perkebunan Provinsi. http://disbun.riau.go.id. Diakses 27 September 2015.

Dirjenbun. 2015. Statistik Perkebunan. Departemen Pertanian. Direktorat Jenderal Perkebunan Indonesia. Jakarta. 4 hal.

Haneda, N.F., C. Kusuma dan F.D. Kusuma. 2013. Keanekaragaman Serangga di Ekosistem Mangrove. Jurnal Silvikultur Tropika, 4 (2): 42-46.

Harahap, I.Y., T.C. Hidayat dan Y. Pangaribuan. 2008. Pertumbuhan dan Produktifitas Kacang Kedelai (Glycine max L.) pada Sistem Tumpangsari dengan Kelapa Sawit Belum Menghasilkan. Jurnal Penelitian Kelapa Sawit, 16 (2): 67-75.

Henuhili, Victoria dan T. Aminatun. 2013. Konservasi Musuh Alami sebagai Pengendali Hayati Hama dengan Pengelolaan Ekosistem Sawah. Jurnal Penelitian Saintek, 18(2): 29-40.

Herman, M. dan D. Pranowo. 2011. Produktivitas jagung sebagai tanaman sela pada peremajaan sawit rakyat di Bagan Sapta Permai Riau. In: Prosiding Seminar Nasional Serealia. Hal 213219.

Kalshoven, L.G.E. 1981. Pest of Crops in Indonesia. Ichtiar Baru: Jakarta. 701 hal. 
Marlina. 2013. Pengelolaan Lahan Sub Optimal untuk Pengembangan Pertanian. In Prosiding Seminar Nasional Lahan Suboptimal "Intensifikasi Pengelolaan Lahan Suboptimal dalam Rangka Mendukung Kemandirian Pangan Nasional", 554558. 4 hal.

Marwoto. 2007. Dukungan Pengendalian Hama Terpadu dalam Program Bangkit Kedelai. Jurnal Iptek Tanaman Pangan, 2 (1): 79-92.

Masfiyah, E., S. Karindah, dan R.D. Puspitarini. 2014. Asosiasi serangga predator dan parasitoid dengan beberapa jenis tumbuhan liar di ekosistem sawah. Jurnal HPT, 2(2):914.

Mawarni, L. 2011. Kajian Awal Varietas Kedelai Tahan Naungan untuk Tanaman Sela pada Perkebunan Kelapa Sawit. Jurnal IImu Pertanian Kultivar, 5(2): 5459.

Radiyanto, I., M. Sodiq dan N.M. Nurcahyani. 2010. Keanekaragaman Serangga Hama dan Musuh Alami pada Lahan Pertanaman Kedelai di Kecamatan Balong-Ponorogo. Jurnal Entomologi Indonesia, 7(2): 116-121.

Sanjaya, $Y$ dan A.L.H. Dibiyantoro. Keragaman Serangga pada Tanaman Cabai (Capsicum annuum) yang Diberi Pestisida Sintetis Versus Biopestisida Racun Laba-Laba (Nephila sp.). Jurnal HPT Tropika, 12(2): 192-199.

Subiyakto. 2011. Biologi Pengendalian Hama Berbasis Ekologi Dalam Mendukung Pengembangan Kapas. Jurnal Litbang Pertanian, 30(3): 81-86.

Suleman, H., R. Iswati dan S. Dede. 2013. Hama Pada Tanaman Jagung Manis (Zea Mays) dengan Sistem Pola Tanam Monokultur dan Tumpangsari. Laporan Hasil Penelitian. Hal 1-17.

Susilo. F.X dan Swibawa. I.G. 2001. Serangan, Kepadatan Populasi, dan Keanekaragaman Serangan Pada Pertanaman Jagung yang Dikelola dengan Olah Tanah Konservasi Versus Olah Tanah Konvensional di Natar, Lampung Selatan. Jurnal Hama dan Penyakit Tumbuhan Tropika, 1(2): 4553.

Swaminathan, S. S. 2011. Impact of Global Warming on The Insect Pest Status on Plants. Indian Journal of Science and Technology, 4(3): 230-235.

Tambunan, D.T., D. Bakti dan F. Zahara. 2013. Keanekaragaman Arthopoda pada
Tanaman Jagung Transgenik. Jurnal Online Agroteknologi, 1(3): 744-758.

Undang-Undang Republik Indonesia Nomor 5 Tahun 1990 tentang Konservasi Sumberdaya Alam Hayati dan Ekosistemnya. Jakarta: Badan Pengendalian Dampak Lingkungan 


\section{$\mathbf{J}$

PEMBERIAN KOMPOS TKKS DAN COCOPEAT PADA TANAH SUBSOIL ULTISOL TERHADAP PERTUMBUHAN BIBIT KELAPA SAWIT (Elaeis guineensis Jacq.) DI PRE NURSERY

Composting EFB And Cocopeat On Subsoil Ultisol To The Growth Of Palm Oil Seedlingsin Pre Nursery

Siziko Andri, Nelvia, Sukemi Indra Saputra

PENGARUH INOKULASI CAMPURAN ISOLAT BAKTERI PELARUT FOSFAT INDIGENUS RIAU TERHADAP PERTUMBUHAN DAN PRODUKSI TANAMAN KEDELAI (Glycine max L. Merr)

Effect of Riau Indigenus Phosphate Solubilizing Bacteria Isolate Mixture Inoculation on Soybean Growth and Yield

Lufita Nur Alfiah, Delita Zul, Nelvia

PROPAGASI IN VITRO ANGGREK (Dendrobium phalaenopsis Fitzg) TERHADAP PEMBERIAN HORMON IBA DAN KINETIN

In Vitro Propagation of Orchid (Dendrobium phalaenopsis Fitzg) on The Addition Iba and Kinetion Hormones

Imam Mahadi

PEMBERIAN BEBERAPA AMELIORAN TERHADAP PERUBAHAN SIFAT KIMIA TANAH GAMBUT

Giving Some Ameliorants To Changes Chemical Properties of Peat Soil

Ervina Aryanti, Yulita, Aulia Rani Annisava

ANALISIS PEMASARAN PADI SAWAH DI KECAMATAN RAMBAH SAMO KABUPATEN ROKAN HULU

Marketing Analysis Of Paddy Field In The Rambah Samo District Rokan Hulu Regency

Darus

KEANEKARAGAMAN SERANGGA PADA TUMPANGSARI TANAMAN PANGAN SEBAGAI TANAMAN SELA DI PERTANAMAN KELAPA SAWIT BELUM MENGHASILKAN Insect Diversity on Intercropping System in Young Palm Oil

Lutfi Arifin, Mokhammad Irfan, Indah Permanasari, Auli Rani Annisava, dan A. Taufiq Arminudin ....... 